\title{
SOME RECENT ADVANCES IN FOETAL PHYSIOLOGY
}

\section{Based on a Lecture given at the Combined Post Graduate School of Queen Charlotte's Hospital and the Chelsea Hospital for Women}

\author{
By S. G. Clayton, M.D., M.S., F.R.C.S., M.R.C.O.G. \\ Assistant Obstetric and Gynaecological Surgeon, King's College Hospital ; Assistant Obstetric Surgeon, \\ Queen Charlotte's Hospital
}

In 190I Ballantyne's 'Plea for a promaternity hospital' led to the first establishment of hospital beds for the specific purpose of studying the physiology and pathology of pregnancy. Although he quickly realized and strongly urged. the value of antenatal care to the mother, Ballantyne's original aim was chiefly to discover means of saving foetal life - to prevent miscarriage and that most terrible of all events the dead birth, and to cure before birth the diseases and deformities of the foetus.' Parsons (1946) has emphasized that infant care must begin before birth, and only by a study of the normal can we hope to understand the abnormal. For this reason a mere obstetrician ventures to review a little of the recent work of physiologists, arbitrarily selecting topics suitable for inclusion in a short article.

Oxygenation of the foetus. Barcroft and many others have made great contributions to this subject. The foetal tissues require large amounts of oxygen, $1.25 \mathrm{ml}$. per kilo per minute at term (Haselhorst and Stromberger 1932), and special physiological mechanisms are necessary to supply the increasing foetal demands, though it cannot be overstressed that there are wide differences between the placentae of different species, and the results of animal experiments must not be applied to man without reserve.

I. Increased oxygen could be supplied by increasing the oxygen content of maternal blood, but actually the oxygen capacity of maternal blood falls during pregnancy to 15.5 volumes per cent. (normal 19 vols. per cent.) because of the lowered red cell count and reduced alkali reserve.

2. An increased flow of maternal blood through the uterus would serve the same pur- pose, and in fact occurs, but in rabbit experiments the flow lags behind the increasing foetal needs, as is shown by the progressive fall in the oxygen content of the blood in the uterine veins. (Barcroft et al., 1933, 1934.)

3. An increased flow of foetal blood through the placenta would have the same effect. The foetal blood pressure rises progressively during pregnancy in the sheep and the volume of blood traversing the placenta increases, though at term the gain is only proportional to the rise in foetal weight. (Barcroft et al., 1939.)

4. The 'diffusion constant' of the placenta might alter, that is the ease with which oxygen can cross the placental barrier. Diffusion is slow in the syndesmochorial placenta of the cow, but this observation cannot reasonably be applied to the human haemochorial placenta: In late pregnancy the trophoblast covering the villi is thinner, but the total area of villi does not increase after mid-pregnancy after which maximal foetal growth occurs.

5. The foetal blood has an increased avidity for oxygen. Foetal blood at term contains over $15.5 \mathrm{gm}$. of haemoglobin per $100 \mathrm{ml}$. and has an oxygen capacity of 21 volumes per cent. It is commonly stated that this is due to a high red cell count, but during early foetal life the count is low, and at term human cord blood is not polycythaemic. The polycythaemia appears within an hour after birth (Wintrobe and Schumacker, 1936). But though the corpuscles are not more numerous, they are larger and have a higher mean haemoglobin content.

The interesting discovery has been made that in many species foetal haemoglobin has different qualities from adult haemoglobin. In the goat, for example, Barcroft and his coworkers (1934) found that the oxygen dis- 
sociation curve of foetal blood shows a 'shift to the left,' while the maternal blood curve shows a 'shift to the right,' meaning that a low oxygen tension foetal blood will take up more oxygen than maternal blood. The curves are differently shaped, so that the foetal curve is steeper at low oxygen pressures. The shift of the maternal curve is due to the reduced alkalinity of maternal blood. The altered foetal curve is due to the presence of a different type of haemoglobin. (Roos and Romijin, 1938. McCarthy, 1933.)

In man the curve for solutions of foetal haemoglobin does not show the same results (Harrowitz, 1935), but the same general statement is true for whole foetal blood; its oxygen dissociation curve lies 'to the left' of that of the mother's blood. (Eastman et al., 1933.) In other words, foetal blood can take up oxygen at tensions at which maternal blood loses oxygen. For technical reasons it is most difficult to discover the actual saturation of the blood entering and leaving the placenta in man. The published results are discussed by Windle (1940) who concludes that unbilical vein blood is about 70 per cent. saturated, a higher figure than is usually given.

The foetal circulation. The course of the foetal circulation has been studied in the foetal lamb by cineradiology after the injection of radio-opaque fluid into the circulation, by Barclay, Franklin and Pritchard (1944). They also made comparative anatomical studies and it is reasonable to apply their conclusions to the human foetus. They firmly support the Wolff-Ziegenspeck theory of the intra-cardiac course of the foetal blood; which states that blood from the superior vena cava leaves the right auricle through the tricuspid valve, while the blood from the inferior vena cava splits into two streams. The larger left stream directly enters the left auricle through the foramen ovale, while the smaller right stream mixes with the blood from the superior vena cava in the right auricle. In the particular point of the splitting of the inferior caval stream this theory differs from both the classical theories of crossed streams (Sabatier) and total mixture (Pohl-Kellogg). It does not conflict with the view that the blood in the left ventricle is more oxygenated than that in the right ventricle. The inferior caval stream splits on the posterior free curved edge of the interatrial septum (crista dividens) which is shown in the diagrams.

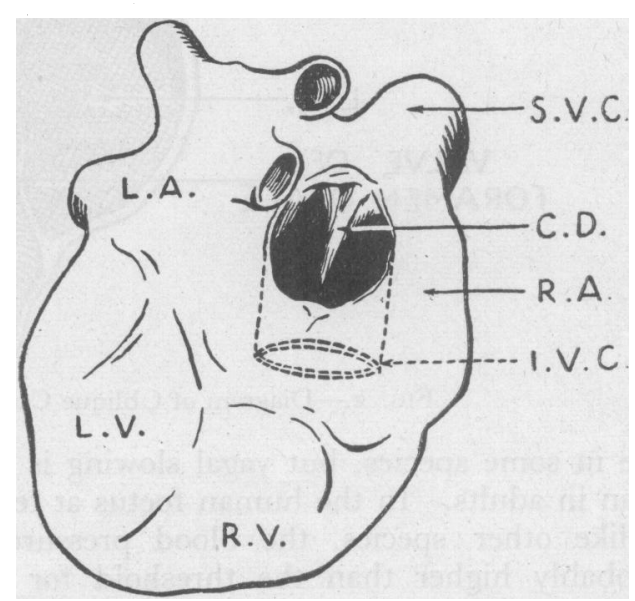

FIG. I.-Diagram to show Barclay et al.'s conception of Crista dividens.

The same workers studied changes that occur in the circulation at birth, and only from lack of space do we fail to review all their conclusions, but two details of particular obstetric interest may be mentioned. Before closure of the umbilical circulation blood normally enters the foetus from the placenta, partly accounting for the postnatal polycythaemia, and providing a foetal reserve of the constituents of haemoglobin. In man $50 \mathrm{ml}$. passes on the average (Haselhorst and Allmeling, 1930). (2) The extra-abdominal parts of the umbilical vessels are not innervated (Spivack, r943), but they contract actively from the placental end first when respiration is established. In man, mechanical stimulation is relatively slight, and the stimulus is uncertain. Cooling, fall of blood pressure or of oxygen tension are not found to be constant factors. (The reviewer wonders if the contraction of the uterus on the placenta may play some part in closing the circulation through it.)

The foetal heart rate has been studied in various species, but incompletely in man. Windle (1940) correlates the observations of several workers and concludes that ' the foetal heart pumps blood about as fast as it can without much control by the nervous system.' The vagi are capable of conduction during foetal 


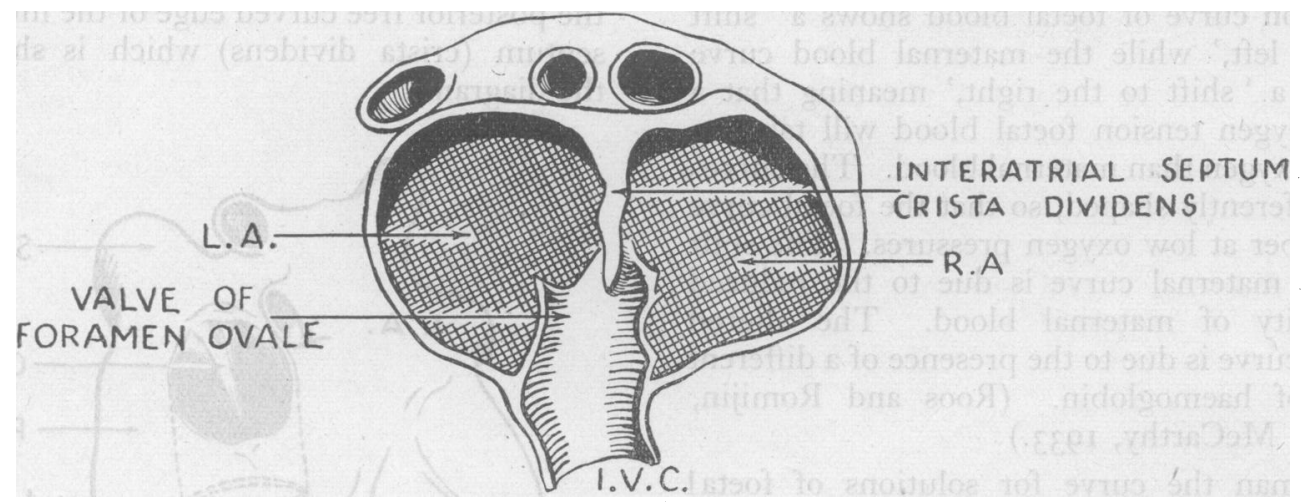

Fig. 2.-Diagram of C blique Cardiac section. Modified from Ziegenspeck 1905 .

life in some species, but vagal slowing is less than in adults. In the human foetus at term, unlike other species, the blood pressure is probably higher than the threshold for the aortic and carotid sinus reflexes, so that slowing of the foetal heart may occur if the blood pressure rises (Marey reflex). This would account for the slowing of the foetal heart with uterine contractions, when the pressure rises in the umbilical veins. Anoxia will also cause bradycardia by direct effect on the pacemaker of the heart (Bauer, 1938) and this may account for the more dangerous and persistent slowing that occurs in prolonged labour.

Foetal respiratory movements. Although Ahlfeld observed respiratory movements in the human foetus in utero in $\mathrm{I} 888$, these movements have only been carefully investigated recently. Reliable observations are difficult to secure, for the mere opening of the uterus sets up abnormal conditions. Barcroft and Barron (1937) and Barcroft (1942) described the respiratory movements of the foetal lamb and have put forward an attractive theory to explain the events observed, but it is fair to remark that alternative theories are possible (Windle, 1940), and that only doubtful confirmation of the events, let alone the theory, has been possible in the human foetus.

The lamb has a gestation period of about 147 days, and the foetus was observed through the amnion after opening the uterus under spinal anaesthesia. The first response to external stimulation is observed on the $34^{\text {th }}$ day, when stimulation of the area just below the eye (Vth nerve ending) causes a single twitch of the head. At first stimulation o other areas is ineffective, but gradually the sensitive area extends, and other muscles also respond, including the diaphragm. After a time rhythmical movements appear, and by the 4 2nd day the foetus easily responds to stimulation, giving an initial writhing movement, which is followed by rhythmical respiratory movements. If the foetus is asphyxiated these responses cease.

Between 50 and 60 days a dramatic change occurs. The foetus becomes unresponsive to stimuli, and this quiescence persists until after delivery. During this stage asphyxia restores the earlier foetal activity, and responses similar to those of the earlier stage reappear. Barcroft and Barron suggested that foetal movements were inhibited by a higher centre, which could be paralysed by asphyxia, when the lower pattern of movement reappeared. They sectioned the brain stem of the foetus above the pons, and found that the responsiveness returned.

There is no space to discuss much recent work on the wider problems of the genesis of reflexes and nervous activity in the foetus. (See Windle, 1940, for discussion and references.) The human foetus is certainly not totally inert in late pregnancy, and apart from limb movements many complex reflexes normally occur, for example swallowing, and any inhibition cannot be unselective. Species differences are very real; the opossum breathes independently 12 days after conception, when it climbs up to the mother's pouch!

Many investigations have been made of the response of the foetal respiratory centre to oxygen lack and carbon dioxide excess, and 


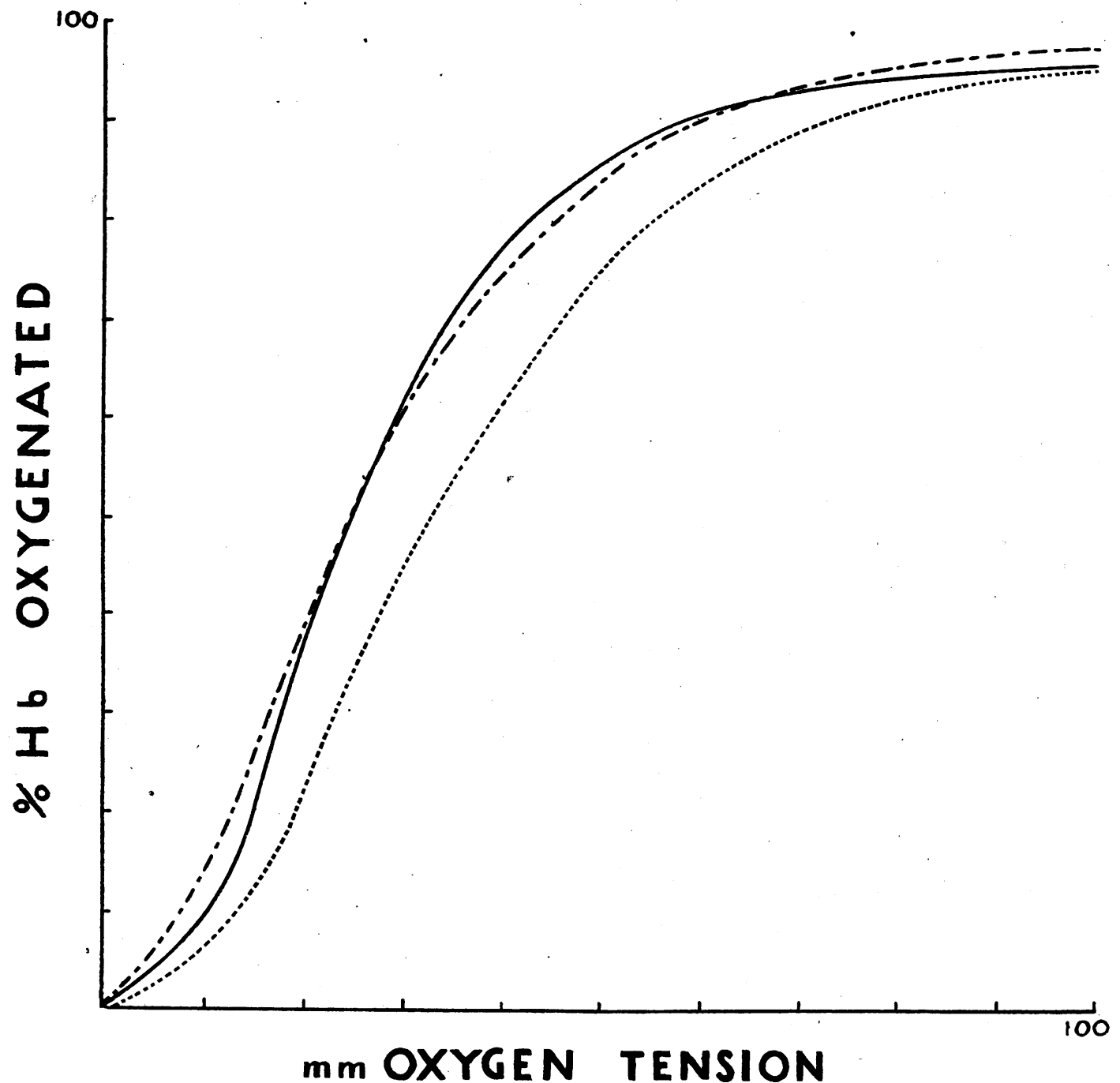

FOETAL BLOOD

PREGNANT WOMAN

NON PREGNANT

Fig. 3.-From Eastmen et al. Johns Hopkins Hospital Bulletin.

the importance of the subject to the obstetrician justifies detailed discussion. Windle and his co-workers (1938) found clear evidence that carbon dioxide stimulated the respiratory centre of the foetal cat. When the mother breathed pure oxygen the foetus was inert; with 8-10 per cent. carbon dioxide in oxygen rapid shallow respiration occurred; with 5-8 per cent. oxygen in nitrogen the mother became cyanosed and foetal gasping occurred. Similar results were obtained in the guinea- pig (Windle et al., 1939), but only inconstant results in the rabbit (Snyder et al., 1937). Barcroft and his colleagues (1940) investigated the foetal sheep and found that respiratory movements did not occur when the blood leaving the brain was 30 per cent. saturated with oxygen, and began when this blood was 10-25 per cent. saturated. Eastman and others (1933) estimated the oxygen and carbon dioxide content of human cord blood at birth, and found that apnoea prevailed when 
the blood was more than 50 per cent. saturated with oxygen irrespective of the carbon dioxide level ; the observations did not permit full deduction of the part played by carbon dioxide at lower oxygen levels.

Though unproven, it is believed that the human foetal centre responds to the same stimuli as the adult centre, though at a higher threshold. If the oxygen saturation is over 50 per cent. there is apnoea irrespective of the carbon dioxide concentration. If the oxygen saturation falls the centre responds to the specific stimulus of carbon dioxide, becoming more sensitive as the oxygen level falls, until about 25 per cent. oxygen saturation is reached. At that level there is gasping reminiscent of Lumsden's primitive type of respiration, and below that level the centre is paralysed and will not respond to any stimulus. Apart from increasing the sensitivity of the centre to carbon dioxide it is doubtful if oxygen lack has any direct effect on the centre, though Barcroft (I942) suggests that gasping respiration may be a direct response to oxygen lack. The part played by aortic and carotid sinus reflexes is unknown.

At the moment of birth the respiratory centre is sensitized by anoxaemia, and bombarded by afferent stimuli. Cutaneous stimuli due to manipulations and cold (Barcroft, I94I) are reinforced by stimuli from muscles and joints newly exposed to the full effect of gravity, and by internal stimuli set up by the changes in the circulation.

Intrauterine respiratory movements may draw liquor amnii into the lungs, but certainly only in small quantities unless asphyxial gasping occurs (Windle et al., 1939).

Maternal diet and foetal development. No review of the mass of new work on foetal metabolism and placental transmission is possible here, and only a brief survey of the effect of maternal diet on the development of the foetus. As regards the total diet, maternal deficiency has little effect on human birth weight, unless at starvation level (Ebbs et al., 1942) (Peoples League, 1942). In the sheep impaired maternal nutrition in the first twothirds of pregnancy has little effect on foetal development, but underfeeding in the last third lowers the birth weight (Wallace, 1944). On the other hand overfeeding did not affect the foetal weight, though the weight of the ewe increased (Hammond, 1933). Summer lambs weigh more on the average than spring lambs, and Toverud (1933) found the same in children. It is suggested that the difference is due to the better quality rather than quantity of food. A child of fuil weight may be born to a poorly fed mother, and this may be explained by the principle of ' competing metabolism,' which states that where there is a common source of supply, more active tissues will take up more nutrient than less active. The foetal tissues have a high metabolic rate and compete successfully against the maternal tissues. Apart from inherited factors, the weight of offspring may be related to that of the mother because of this principle. The foal of a shire stallion and Shetland mare is small, whereas the foal of a Shetland stallion and shire mare is large ; the rapid metabolism of the smaller Shetland mare competes more successfully with that of the foetus (Walton and Hammond, 1938).

Apart from gross weight, inadequate diet may affect development and postnatal health. The possible relationship of dietary deficiency to anatomical abnormality is mentioned later. Huggett (194I) has given figures which indicate that over two-thirds of the foetal substance is built up in the last trimester of pregnancy :

Composition of the human foetus in gms.

\begin{tabular}{|c|c|c|c|c|c|}
\hline $\begin{array}{l}\text { Lunar } \\
\text { month }\end{array}$ & $\begin{array}{c}\text { Body } \\
\text { wt. }\end{array}$ & Water & Protein & Fat & Ash \\
\hline Fifth & 300 & & 22 & $3 \cdot 5$ & I: 5 \\
\hline x & 1000 & & 100 & 25 & 30 \\
\hline Tent & 3200 & 2420 & 400 & $35^{\circ}$ & 90 \\
\hline
\end{tabular}

Through-

Average daily deposition in gms.

$\begin{array}{lllll} & & & \\ \begin{array}{c}\text { out preg- } \\ \text { nancy . I I.4 }\end{array} & 8.6 & 1.4 & \text { I.25 } & 0.32 \\ \begin{array}{c}\text { Last three } \\ \text { months. 26.2 }\end{array} & 19.3 & 3.6 & 3.9 & 0.7 \mathrm{I} \\ \begin{array}{c}\text { Last } \\ \text { month.. } 35.7\end{array} & 23.6 & 6.4 & 5.0 & 2.0\end{array}$

The same applies to the foetal content of nitrogen, calcium, phosphorus and iron (Swanson and Iob, 1939). The following approximate figures illustrate the point :

\begin{tabular}{|c|c|c|c|c|}
\hline $\begin{array}{l}\text { Lunar } \\
\text { month }\end{array}$ & Nitrogen & Calcium & Phosphorus & Iron \\
\hline Fifth & .. 2 & 2 & I & 0.005 \\
\hline Seve & $\ldots \quad$ I I & 5 & 3 & 0.05 \\
\hline Tent & $\ldots 60$ & 25 & 15 & 0.3 \\
\hline
\end{tabular}


During the last third of pregnancy the foetus builds up a store of various essential minerals and vitamins, many of which are short during the 'negative phase' that follows birth. If there is a deficient maternal diet, or if premature birth occurs, the infant has poor reserves and is more likely to suffer from postnatal deficiency disease, and to show such disease earlier than other infants. For example, with maternal iron deficiency postnatal anaemia may occur (Parsons, 1932), and Ebbs et al. (194I) state that anaemia and rickets are more frequent in the children of women taking a poor diet than in the children of those whose diet was supplemented in the last three months of pregnancy. Mellanby (193I) showed how antenatal nutrition can affect the teeth, even of the permanent dentition.

Developmental abnormalities. Lastly, we may perhaps refer to a subject that is as much pathological as physiological. As Professor of Teratology at Edinburgh, Ballantyne would have been interested in modern embryology, which is largely physiological in method. By unconscious convention we have loosely reserved the term 'congenital abnormality' for structural defect of unknown cause ; and indeed as soon as a cause is found the disease is classified under some other heading. For example hydrops foetalis was formerly regarded as an anomaly of development, we now speak of haemolytic disease.

Developmental abnormalities can be divided into two groups :

I. Primary, due to the genetic structure of the zygote, which we have no present means of altering.

2. Secondary, due to adverse influences acting on the embryo, and here we have more knowledge, partly based on the experiments of Spemann, Harrison, and Child. It was found that if a developing embryo was exposed to the action of a noxious agent, abnormalities of structure were produced which were independent of the nature of the agent, and only depended on the stage of development reached. Such diverse agents as heat and cold, radiation, and various chemical substances were used. The embryo shows ' axial gradients,' and at any particular stage of development the most active regions of the embryo are relatively electronegative and are more susceptible to toxic agents. Although the experiments have not been confirmed in mammals, the same principle that 'teratological agents are nonspecific' may be found true for human embryos. What agents are possible in man ?

I. Abnormal maternal diet. There is little evidence that human anatomical abnormalities are due to maternal dietary deficiencies; though Maxwell (1929) described foetal rickets in cases of maternal ostemalacia, this is at least in theory a reversible foetal change. It is doubtful how far conclusions based on animal dietary experiments can be applied to human pregnancy. For example the effect of vitamin $\mathrm{E}$ deficiency in producing abortion in rats has been the basis for the therapeutic use of this substance. In the rat part of the placenta is vascularized by yolk sac vessels, and in vitamin $\mathrm{E}$ deficiency these vessels are strangled by proliferation of yolk sac mesoderm. The human placental vessels are of allantoic origin, and vitamin $\mathrm{E}$ deficiency would not be expected to have the same result in man. Again in species with epitheliochorial (pig) or syndesmochorial (cow) placentae, maternal iodine deficiency causes foetal athyreosis, but this does not occur in man, as maternal thyroxin can cross the placental barrier in man. (Smith, I919.) In animals gross nutritional deficiencies will produce severe abnormality; for example, ocular defects in the litter of a sow with vitamin A lack, and skeletal defects with various deficiencies in rats (Warkany et al., r943; Warkany, 1945). Further studies are needed in man.

2. Impaired placental circulation. The effect of impaired placental circulation in producing abnormalities is illustrated by the acardiac monstrosity found with uniovular twins, and by cases of advanced ectopic gestation, in which as many as half of the infants are abnormal.

3. Intrauterine pressure and 'amniotic adhesions.' The possibility that a few abnormalities such as talipes are sometimes due to intrauterine pressure cannot be totally denied, but Streeter (1935) has shown that 'intrauterine amputations' and 'amniotic adhesions' are not due to pressure but to a failure of vascularization and differentiation in the tissues involved. Such deformities are often multiple, and are possibly due to the 
action of some adverse agent on the limb buds at their critical stage of active proliferation.

4. Virus or other infection. Gregg (I94I) first noticed the association between maternal rubella in early pregnancy and congenital cataract and heart disease. Other observers have confirmed his findings and attributed other defects such as deafness, mental defect, microcephaly, and dental abnormalities to the same cause (Swan et al., 1943, 1944, 1946 ; Martin, I945). There is some suggestive evidence that other virus infections may also produce defects (see Editorial, Lancet, 1947), but we are not concerned here with detailed discussion of this evidence but only with the broad fact that intrauterine infection will disturb the normal physiology of development. The majority of abnormalities due to rubella occur with infection during the first three months; with later infection many infants escape. Swan found the average time of infection in cases of cataract and of deafness correspond with the critical embryonic ages for the development of eye or ear, and Evans (1944) found the same for dental defects. With later infection, when organogenesis is largely complete, gross abnormalities of structure are not produced, and foetal reaction resembles that of the newborn.

5. Hormones. In some species male sexual hormones produced by one twin will affect a second twin, producing a sterile freemartin. (Lillie, r917, I923; Hughes, 1929.) Pseudohermaphroditism has been experimentally produced in rats by injection of heterosexual hormones (Greene and Burrill, 1939), but there is no evidence that human anatomical abnormalities are produced by maternal or twin hormones.

There is no real division between the gross abnormalities that we have been discussing and foetal disease of later onset. Once the main embryonic systems are laid down adverse agents could not be expected to produce gross defects, but the more subtle abnormalities of the central nervous system, for example, are of the same essential nature, in that tracts developing at the particular time are most damaged. But this idea must not be forced too far; in later foetal life adverse agents may act more selectively than in early embryonic life.

This review is not presented as a complete or even a balanced account of recent advances in foetal physiology, but only in the hope of showing the interest and potential practical value of these physiological researches. Experimental investigation of human pregnancy will always be difficult, if not impossible, and only by a wide survey of comparative physiology can reasonable deductions about the human foetus be made.

\section{BIBLIOGRAPHY}

AHLFELD, F. (1888), Verhandl. deutsh. Geselsch. Gynak., 2, 203. BALLANTYNE, J. W. (1901), Brit. Med. Fourn., 1, 813

BARCLAY, A. E., FRANKLIN, K. J., and PRITCHARD, $M$. M. L. '(1944),' The Foetal Circulation.' Oxford : Blackwell. BARCROFT, J., HERKEL, W. and HILL, R. M. (1933), $\mathcal{F}$. Physiol., 77, 194.

BARCROFT. J., ELLIOTT, R. H. E., FLEXNER, L. B, HALL, F. G., HERKE L. W., MCCART'HY, E. F., MCCI URKIN, T. and TALAAT, M.'(1934), $\mathcal{F}$. Physiol., 83, 192.

BARCROFT, J., FLEXNER, L. B., HERKEL, W., MCCARTHY, E. F. and MCCLURKIN, T. (1934), F. Physiol., 83, 215.

BARCROFT, J. and BARRON, D. H. ( $1937, \mathcal{F}$. Physiol., 91, 329. BARCROFT, J., KENNEDY, J. A. and MASON, M. F. (1939), f. Physol., 95, 173, 269.

BARCROFT, J., BARRON, D. H., COWIE, A. T. and FORSHẢM,'P. H. ( 1940), $\mathcal{f}$. Physiol., 97, 338 .

BARCROFT, J. (194I), Lancet, 2. 92.

BARCROFT, J. (1942), Lancet, $2,117$.

BAUER, D. J. (1938), F. Physiol., 93, 90.

BAUER, D. J.( 1938), F. Physiol., 95, 187.

EASTMAN, N. J., GEILING, E. M. K. and DELAWDER, A M. (1933), fohns Hopkins Hosp. Bull. 47, 221.

EBBS, J. H., TISDALL, W. F. and SCOTT, W. A. (I94I), $\mathcal{F}$. Nutrit, $22,515$.

EBBS J. H., MOYLE, W. J., et al. (1942), Canad. M.A.f., 46, I.
EDITORIAL, Lancet (1947), 1, 639.

EV.ANS, M. W. (1944), Med. F. Austral., 1, 409.

GREGG, N. M. (1941), Trans. Ophth. Soc. Austral., 3, 35.

GREENE, R. R. and BURRILL, M. W. (1939), Amer. F. Physiol. I 26, 452, 510.

HAMMOND, J. (1933), ' Growth and Development of Mutton Qualities in Sheep.' Edinburgh.

HASELHORST, G. and ALLMELING, A. (r930), Ztschr. Geburtsh. Gynak., 98, 103.

HASELHORST, G. and STROMBERGER, K. (r932), Ztschr. Geburtsh. Gynak., 102, 16.

HUGGETT, A. ST. G. (1941), Physiol. Rev., 21, 438-462

HUGGETT, A. ऽT. G. (1944), Proc. Nutrit. Soc., 2, 20.

HUGHES, W. (1929), Anat. Rec., 41, 213.

LANCET, Edit orial (1947), $1,639$.

LILLIE, F. R. (1923), Biol. Bull., 44, 47.

LILLIE, F. R. (1917), F. Exp. Zool., 23, 37 1.

MCCARTHY E. F. (1923), F. Physiol., 80, 206.

MARTIN, S. M. (1945), Brit. Med. fourn., r, 855.

MAXWELL, J. P. (1 929), Proc. Roy. Soc. Med., 23, 639.

MELLANBY, M. (1931), Brit. Med. fourn., 2, 595.

PARSONS, L. (1946), F. Obst. Gyn. Brit. Emp., 53, 1.

PARSONS, L. (1932), Acta Pa diat., 13, 378.

PEOPLES' LEAGUE OF HEALTH, La ${ }^{23}$ cet (1942). 
ROOS, J. and ROMIJN, C. (1938), F. Physioi., 92, 249.

SMITH, G. E. (rigr), Endocrinol., 3, 362.

SNYDER, F. F. and ROSENFELD, M. (1937), Amer. F. Physiol., II9, I 53 .

SPIVACK, M. (1945), Anat. Rec., 85, 85.

STREETER, G. L. (1935), Harvey Lectures, 1933-34, p. 204, Baltimore.

SWAN, C., TOSTEVIN, A. L. and BLACK, G. H. B. (1946), Med. . Austral., 2, 889 .

SWAN, C., TOSTEVIN, A. L. and BLACK, G. H.'B. (1944), Med. F. Austral., I, 409

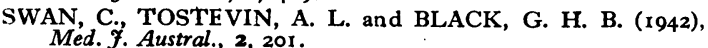

SWANSON, W. W. and 1OB. V. (1939), Amer. F. Obst. Gyn., 38, 382 .

TOVERUD, K. (1933), Amer. F. Dis. Child., 46, 954.
WALlACE, L. R. (1944), F. Physiol., ro4, 34 P.

WALTON, A. and HAMMOND, J.(1938), Proc. Royal Soc. B., 125, 311 .

WARKANY, J. ( 1 945), Amer. F. Dis. Child., 99, 330.

WARKANY, J., NELSON, R. C. and SCHRAFFENBERGER, E. (1943), Amer. F. Dis. Child., 65, 822.

WINDLE, W. F. (1940), 'Physiology of the Fetus.' Saunders : Philadel phia.

WINDLE, W. F., MONNIER, M. and STEELE, A. G. (1939), Phys. Zool., I1, 425.

WINDLE, W. F. BECKER, R. F., BARTH, E. E. and SCHUTZ, M. D. (1938), Surg. Gyn. Obst., 69, 705.

WINTROBE, M. M. and SCHUMACKER, H. B. (1936), Amer. 7. Anat., 53, 313 .

WINTROBE, M. M. and SCHUMACKER, H. B. (1935), fourn. Clin. Invest., 19, 837 .

\section{TEACHER AND STUDENT}

There are two aspects in which we may view the teacher-as a worker and'instructor in science, and as practitioner and professor of the art; and these correspond to the natural division of the faculty into the medical school proper and the hospital.

Sir William Osler.

\section{NOTICE TO CONTRIBUTORS}

I. All papers for publication must be in the hands of the Editor at least ten weeks before the proposed date of publication.

2. All papers should be typewritten as concisely as possible, with double spacing and a good margin. Subheadings should be clearly shown.

3. Papers may be illustrated at the discretion of the Editor, with six or less illustrations, electrocardiographs, X-rays, or line drawings, etc. Blocks may be obtained after use at the usual trade rates.

4. References to papers or other publications in the text must be shown by giving the name of the author and the year of publication (with or without brackets). At the end of the paper these references should be arranged alphabetically according to the R.S.M. system.

Thus : (If to a Journal)

Author's name (year), journal, page, e.g. : ATKINSON, J. (1921), F. Biol. Chem., 47, r 34. (If to a book).

Author's name (date of publication), title of book, place of publication, e.g. : BROWN, C. D, (1935), "Diseases of the Skin," London.

5. Reprints of articles may be obtained provided notice is given when returning the corrected galley proof.

6. Contributors should send their manuscripts to :-

The EDitor,

Post Graduate Medical Journal,

I, Wimpole Street,

London, W.I, England. 